\title{
Willingness to pay for sustainable housing
}

\author{
Svante Mandell ${ }^{\text {a) }}$ och Mats Wilhelmsson ${ }^{\text {b) }}$
}

\begin{abstract}
Over the last decades there has been an increasing focus on how to build a sustainable society and in particular on how to design policies that pushes the society into a more sustainable direction. The present paper aims at analysing differences between house buyers when valuing environmental characteristics associated with the house as such. The theoretical framework used is based on the hedonic modelling, but we are also estimating the second stage by assuming a translog utility function. In doing that we are able to estimate the non-marginal willingness to pay for environmental housing attributes and whether environmental aware household have a higher willingness to pay or not. The conclusion to be drawn from the analysis is that there is a positive willingness to pay for environmental attributes. Hence, there may be room for policy measures such as information campaigns. However, it seems to be more effective concerning environmental housing attribute that do not require large investment.
\end{abstract}

a) vti - Swedish National Road and Transport Research Institute, Box 55685, SE-102 15, Stockholm, Sweden, svante.mandell@vti.se,+46855577038

b) Center for Banking and Finance, Royal Institute of Technology, KTH, Sweden 


\section{Introduction}

Over the last decades, not least since the Brundtland report was published in the late 1980:s, WCED (1987), there has been an increasing focus on how to build a sustainable society and in particular on how to design policies that pushes the society into a more sustainable direction. It seems natural that such policies should target areas where they can make a difference. Arguably, housing is one such area, partly because its current substantial impact on the environment may be lowered using existing and relatively cheap measures and partly due to housing being a highly durable good that will impact the environment for many years to come.

If one is to succeed in building a sustainable society, it is essential that the individuals - the consumers - find it in there own interest to act in a sustainable manner. Typically, economic policy instruments, for example, emission taxes or cap and trade regimes, achieve exactly this. By putting a price on being 'unsustainable', for instance, emitting greenhouse gases, incentives for a more sustainable behaviour are provided. It is easily shown that such economic policy instruments in most situations are superior to other approaches such as command and control. In particular, the flexibility provided by economic instruments, following from that the agents are free to choose whether to pollute and pay a tax or not, is a key feature in reaching a cost effective outcome. However, depending on the situation, there may be room for other policy measures, as for instance information campaigns.

To design an appropriate policy package for sustainable housing, the policy maker needs to know how the agents in the housing markets are likely to respond to policies. This is the focus of the present paper. By the use of a unique data set that combines high quality register data on the characteristics of 618 single family houses with the result of a survey that both adds further housing characteristics as well as information regarding the individual buyers, we are able to take a series of important steps towards a better understanding of the willingness to pay for sustainable features of housing. The data allow us to analyse the impact from household characteristics such as income, level of education and number of children, on the behaviour of different buyers. To add yet another layer to the analysis, we distinguish potential differences in willingness to pay between buyers that (state that they) perceive themselves as 'environmentally aware' and those that do not. This may provide some valuable input for policy makers. Let us, for the moment, assume that those who claim themselves to be environmentally aware actually are better informed about how their behaviour affects the environment. If the aware group shows a different (presumably higher) willingness to pay for environmental housing attributes ${ }^{1}$, this opens up for information campaigns being a part of a justifiable policy. If, on

1 This seems to be the case for consumer goods, as noted in The Wall Street Journal, April 24-25, 2010; "About $17 \%$ of U.S. consumers said in a recent survey that they were willing to pay more for environmentally friendly products, up from $10 \%$ last fall and $13 \%$ a year earlier" 
the other hand, there are no differences between the groups one needs to find some other way of justifying spending money on such campaigns.

The present paper thus aims at analysing differences between house buyers when valuing environmental characteristics associated with the house as such. Even though there are several similarities, not least regarding the technical approaches, it differs from the large literature that uses house prices to find estimates for the willingness to pay for environmental quality rather than, as here, for physical housing attributes ${ }^{2}$. This literature includes studies addressing air quality, for example, Smith and Deyak (1975), Kiel and McClain (1985). Chattopadhyay (1999, 2000), Beron, Murdoch and Thayer (2001) and Brasington and Hite (2005), water pollution, for instance, Hoehn, Berger and Blomquist (1987), and sites for toxic waste, for example, Kohlhase (1991), Nelson, Genereux and Genereux (1992) and Hite et.al. (2001).

This paper is also related to a large literature discussing willingness to pay for environmental policy, Longo et.al. (2008) and Scarpa and Willis (2010). Similar questions that we address in the present paper are relevant for other kinds of composite goods than housing. A prominent example may be willingness to pay for environmental attributes of new cars, as has been addressed in for example Potoglou and Kanaroglou (2007) and Axsen et.al. (2009).

The remaining paper is structured as follows. Section 2 provides the theoretical framework, leading up to a function that is empirically testable. Section 3 presents the data and the econometric analysis. Policy implications are discussed in Section 4. Section 5 concludes.

\section{Theoretical framework}

A central question addressed in this paper is; do people that claim themselves to be environmentally aware exhibit a higher willingness to pay for attributes that may be considered environmentally friendly? To answer this question, several steps are required. First, we need some way to compare different buildings from a sustainability point of view. This may be done in more or less arbitrary and/or subjective ways. In the present paper we use principal component analysis to reach a classification determined by the data. Second, we need to establish what the market participants have paid for environmental housing attributes. To disentangle the different attributes, we will use a hedonic price equation.

\footnotetext{
${ }^{2}$ There is a literature on energy-savings measures, see for instance Banfi et.al. (2008), which is close to the present study. However, the technical approach is different from ours.
} 
As a third step, we may turn to the willingness to pay. This requires a second equation, which enables us to study how socioeconomic attributes of the house buyers may influence their willingness to pay for sustainable housing attributes, see Rosen (1974). Here we make an assumption that each individual strives to act his or her utility. This would suggest that environmentally aware individuals should purchase housing with a higher degree of environmental attributes. However, this approach is not sufficient. For instance, as individuals (or households in our dataset) have different incomes, it could be that high income households buy housing with more environmental attributes, not because they are more environmentally aware but because they buy more of all attributes. Thus, we need a better hypothesis regarding how environmentally aware households are likely to behave. The one we suggest is that for any given allocation of attributes, an environmentally aware household would be willing to sacrifice more non-environmental attributes in order to achieve one extra (marginal) unit of an environmental attribute than would a non-aware household.

To formalize this, let us assume that a household spend their income on buying a house with a set of attributes while the remaining income is spent on other consumption ${ }^{3}$. Let us denote the expected income over the household's lifetime by $I$, other consumption by $x$ which we treat as a numeraire good (i.e., its price is normalized to 1 ), and the price of the house $P$. The house price is a function of housing attributes captured by a vector $z$ which thus contains both 'normal' and environmental attributes. A household's budget constraint may be written as:

$$
x+P(z)=I
$$

Given this budget constraint, the household strives to maximize its utility, denoted $U$, which is a function of $x$ and $z$. Solving this maximization problem yields that the following condition must be fulfilled in optimum:

$$
\frac{\partial P(z)}{\partial z_{i}}=\frac{\partial U / \partial z_{i}}{\partial U / \partial x}
$$

The left hand side of (2) is the implicit marginal price for attribute $z_{i}$. The right hand side is the marginal utility from attribute $z_{i}$ over the marginal utility of good $x$, that is, the marginal rate of substitution between $z_{i}$ and $x$. The implicit price for attribute $z_{i}$ is reached by differentiating the hedonic price equation with respect to $z_{i}$. To formalize the right hand side however requires an assumption about the specific form of the utility function. In the following we will use a translog function (first suggested by Lau and Mitchell (1971)). This flexible functional form is frequently used

\footnotetext{
${ }^{3}$ Thus, we are assuming that a household buys only one house. In the subsequent empirical part we use the current (monthly) income to derive a proxy for the lifetime income and thereby we implicitly assume no transfers between generations.
} 
to capture utility (often indirect utility) and production functions in empirical studies. There is a whole family of different translog functions; all share common features but differ in exact specification. The one we use in the present paper is the following:

$$
\begin{aligned}
U(x, z)= & \log x+\sum_{i=1}^{k}\left(\alpha_{i}+\phi_{E, i} E+\phi_{F, i} F+\phi_{H, i} H\right) \log z_{i} \\
& +\frac{1}{2} \sum_{i=1}^{k} \sum_{j=1}^{k} \beta_{i j} \log z_{i} \log z_{j}
\end{aligned}
$$

Where $k$ is the number of housing attributes, $E$ is a dummy variable denoting whether or not the household states that they perceive themselves as environmentally aware, $F$ measures family size, and $H$ measures the number of persons in the household with higher education. The parameters that specify the utility function are $\alpha_{i}, \phi_{E, i}, \phi_{F, i}, \phi_{H, i}$, and $\beta_{i j}$. Where $\beta_{i j}=\beta_{j i}$. It is easily shown that a positive value of $\phi_{E, i}$ implies that for environmentally aware households, to be exact, when $E=1, \log x$ must decrease more when $z_{i}$ is increased for $U$ to be kept at some arbitrary level ${ }^{4}$. That is, the functional form captures the notion of environmental awareness as put forward above. Differentiating (3) with respect to $z_{i}$ and $x$ respectively yields an analytical expression for the marginal rate of substitution, that is, the right hand side of (2):

$$
\frac{\partial U / \partial z_{i}}{\partial U / \partial x}=\frac{x}{z_{i}}\left(\alpha_{i}+\phi_{E, i} E+\phi_{F, i} F+\phi_{H, i} H+\sum_{j=1}^{k} \beta_{i j} \log z_{j}\right)
$$

It will prove useful to rearrange (2) so that it is expressed in terms of an expenditure ratio, i.e., relating the expenditure on a particular attribute to the expenditure on all other consumption. This is achieved by multiplying both sides with $z_{i}$ and dividing by $x$, which together with (4) yields the following equation:

$$
\frac{z_{i}}{x} \frac{\partial P(z)}{\partial z_{i}}=\left(\alpha_{i}+\phi_{E, i} E+\phi_{F, i} F+\phi_{H, i} H+\sum_{j=1}^{k} \beta_{i j} \log z_{j}\right)
$$

that will be estimated in the subsequent empirical analysis.

Once the parameters of the expenditure function are estimated, we may derive the willingness to pay for the attributes. The willingness to pay for a marginal change in the level of an attribute follows from

\footnotetext{
${ }^{4}$ Let $\mathrm{U}(x, z)$ be equal to an arbitrary positive constant, $K$, and rearrange (3) such that $\log x$ is on the LHS. Differentiating with respect to $z_{i}$ and $E$ yields $-\Sigma\left(\phi_{i} / z_{i}\right)$, which thus is the additional impact on $\log x$ from a change in $z$ when $E=1$ rather than 0 . As all $z_{i}$ are positive, this expression is negative if $\phi>0$, i.e., a larger decrease in $\log x$ is required if $E=1$. This translates into steeper indifference curves for environmentally aware households $(E=1)$ for any allocation of $x$ and $z$.
} 
the marginal rate of substitution given in (4). For non-marginal changes, the willingness to pay is given by $\int_{a}^{b} \partial U / \partial z_{i} / \partial U / \partial x d z_{i}$ where the level of attribute $z_{i}$ is changed from $a$ to $b$. Assuming $\mathrm{b}=$ $1.25 a$ the willingness to pay is approximately ${ }^{5}$ given by

$$
x \log [1.25]\left(\varphi+\frac{\beta_{i, i}}{2}(\log [1.25]+2 \log [a])\right.
$$

where $\varphi=\alpha_{i}+\phi_{E, i} E+\phi_{F, i} F+\phi_{H, i} H$.

\section{The Empirical Analysis}

\subsection{The Data}

The empirical analysis is based on a cross-sectional data-set initially covering 968 transactions of single-family houses in 2000 in Stockholm, Sweden. Besides the standard transaction data, such as house price, size, quality, and distance to central business district (CBD), the data set is supplemented by data relating to housing characteristics and household attributes collected by a postal survey. The survey contained several questions about the household (including family size, educational background, income, and environmental awareness) and environmental related property characteristics. It was posted to all households that bought a single-family house in 2000 and still owned it in 2003. The response rate was about 65 per cent, leaving a total number of observations included in the sample of 618. The data set has earlier been used in Wilhelmsson (2008a and 2008b). Table 1 summarizes the data.

The average price is SEK 2.5 million $^{6}$; however, the variation around the average price is substantial. The typical single-family house in the sample is 50 years old, with approximately 120 square meters of living space over five rooms. On average, the single-family houses are located around 8.8 kilometers from CBD. Around 5 per cent of them have sea view and 29 per cent are located close to a major road. About half of the houses were, at the time of purchase, in need of interior or exterior maintenance according to the buyers.

\footnotetext{
${ }^{5}$ Following Chattopadhyay (1999). The expression relies on an assumption that the willingness to pay for a given attribute is small relative to other consumption, $x$.

${ }^{6}$ At the time of writing, 1 SEK is approximately $€ 0.1$ or USD 0.14 so the average price corresponds to around $€ 250000$ or USD 350000 .
} 
Table 1. Descriptive Statistics

\begin{tabular}{|c|c|c|c|c|c|}
\hline Variable & $A b b r$. & Unit & Average & $\begin{array}{l}\text { Standard } \\
\text { Deviation }\end{array}$ & $\begin{array}{c}\text { Average } \\
\text { Environmental } \\
\text { Aware }\end{array}$ \\
\hline Housing Price & $P$ & SEK & $2,547,583$ & $1,214,785$ & $2,542,297$ \\
\hline \multicolumn{6}{|l|}{ Housing Attributes } \\
\hline Living area & LA & $\begin{array}{l}\text { Square } \\
\text { meter }\end{array}$ & 118.86 & 42.80 & 118,79 \\
\hline Other area & OA & $\begin{array}{l}\text { Square } \\
\text { meter }\end{array}$ & 58.42 & 32.54 & 57,83 \\
\hline No. of rooms & $\mathrm{R}$ & Number & 5.03 & 1.33 & 5.03 \\
\hline Lot size & LS & $\begin{array}{l}\text { Square } \\
\text { meter }\end{array}$ & 724.08 & 265.51 & 730.61 \\
\hline Quality & $\mathrm{Q}$ & Index & 27.62 & 5.90 & 27,61 \\
\hline Age & $\mathrm{A}$ & Year & 51.34 & 18.33 & 51,41 \\
\hline Distance to CBD & Dist & Meter & 8753 & 2696 & 8755 \\
\hline Sea view & Sea & Binary & .053 & .23 & .055 \\
\hline Traffic & $\operatorname{Tr}$ & Binary & .286 & .45 & .293 \\
\hline Need of maintenance & $\mathrm{Nr}$ & Binary & .464 & .50 & .459 \\
\hline \multicolumn{6}{|l|}{$\begin{array}{l}\text { Environmental Related Housing } \\
\text { Attributes }\end{array}$} \\
\hline Ventilation with heat- exchanger & Vent & Binary & .073 & .26 & .087 \\
\hline Insulation roof (extra) & Insr & Binary & .249 & .43 & .236 \\
\hline Insulation walls (extra) & Insw & Binary & .266 & .44 & .266 \\
\hline Water reduced WC & $\mathrm{WC}$ & Binary & .196 & .40 & .278 \\
\hline $\begin{array}{l}\text { Water reduced water } \\
\text { taps }\end{array}$ & WB & Binary & .179 & .38 & .206 \\
\hline Central heating & $\mathrm{CH}$ & Binary & .003 & .06 & .002 \\
\hline Heat pump & $\mathrm{HP}$ & Binary & .092 & .29 & .101 \\
\hline Solar energy & SE & Binary & .002 & .04 & .002 \\
\hline $\begin{array}{l}\text { Waterborne heating } \\
\text { distribution }\end{array}$ & WHD & Binary & .788 & .41 & .889 \\
\hline $\begin{array}{l}\text { Airborne heating } \\
\text { distribution }\end{array}$ & AHD & Binary & .016 & .13 & .000 \\
\hline Three-glass window & $3 \mathrm{~W}$ & Binary & .213 & .41 & .333 \\
\hline \multicolumn{6}{|l|}{ Household Characteristics } \\
\hline Income per month & IM & SEK & 59,246 & 20,208 & 59,350 \\
\hline Lifetime income & LI & M.SEK & 14.22 & 4.85 & 14.05 \\
\hline Family Size & $\mathrm{S}$ & Number & 3.713 & 1.44 & 3.773 \\
\hline Higher Education & E & Number & 1.32 & 0.78 & 1.34 \\
\hline $\begin{array}{l}\text { Environmental Awareness } \\
\text { (self reported) }\end{array}$ & EA & Binary & .792 & .40 & - \\
\hline Number of observation & & & 618 & & \\
\hline
\end{tabular}

The data set contains information about eleven different housing characteristics that are related to the environment in some way. As many as 79 per cent of the houses have a waterborne heating distribution system, which is superior to electrical heating in terms of being more efficient and flexible. Around 20-25 per cent of the houses have retrofitted extra insulation in roofs and walls and three-glass windows. Almost 20 per cent of the houses have water reduced WC and water taps. Less common is ventilations with heat-exchanger and heat pump (less than 10 per cent). Houses using solar energy are even less common (less than 1 per cent). 
The average household consists of 3.7 persons with a standard deviation of 1.4. The average household income is equal to SEK 60,000 per month and around 30 per cent of the household have an income that is higher than SEK 80,000 (average plus one standard deviation). The household's lifetime income is estimated as the present value of the current income at a 6 per cent discount rate. Our measurement of lifetime income is more a multiple of current income and perhaps not an accurate measure of permanent income. The lifetime income is estimated to be around 14 million SEK. A very high proportion of the individuals in the households have a higher education (university degree). On average, 1.3 persons per household have a university degree.

Four questions were asked about environmental awareness. The first question asked whether or not the respondents considered themselves environmentally aware. Response options were yes ors no. Around 80 per cent of the buyers regard themselves as environmental aware. On average, environmentally aware households have higher monthly income, are better educated and are larger. However, these differences are small and not significant. Moreover, environmentally aware households are not buying other types of houses when it comes to size and indoor quality, but it seems that the buy more environmental housing attributes. The other three questions asked whether the household were composting kitchen waste, were using energy saving light bulbs and/or were separating waste. All questions were answered with yes or no. In the subsequent analysis, these latter questions will be used as instrument variables.

\subsection{Principal Component Analysis}

The environmental housing characteristics in the data set show a high degree of multicollinearity, which complicates the analysis and its interpretation. Furthermore, all our environmental housing attributes are binary variables. This causes problems when estimating the utility parameters. To remedy this, we have used the principal components in the hedonic price equation. Principal component analysis (PCA) is a statistical method that from a number of variables develops a smaller set of variables (called principal components) taking the variance of the original variables into account. Each principal component is a linear combination of the original variables. The technique can be used for variable reduction, but here we use it to mitigate the problem of multicollineraity between the environmental housing attributes (see Dunteman, 1992). It also transforms a set of binary variables into a set of continuous variables, which facilitates the interpretation. The principal components are by definition not correlated to each other. A real estate application of the principal component analysis can be found in, for example, Goodman (1978), Des Rosiers et al (2000) and Bourassa et al (2003). 
Table 2. Principal Component Analysis

A. Explanatory power of each factor

\begin{tabular}{lccc}
\hline Component & Eigenvalue & Proportion & Cumulative \\
\hline M1 & 1.950 & 0.177 & 0.177 \\
M2 & 1.538 & 0.140 & 0.317 \\
M3 & 1.333 & 0.121 & 0.438 \\
M4 & 1.019 & 0.093 & 0.531 \\
M5 & 0.992 & 0.090 & 0.621 \\
M6 & 0.968 & 0.088 & 0.709 \\
M7 & 0.752 & 0.068 & 0.777 \\
M8 & 0.742 & 0.067 & 0.845 \\
M9 & 0.657 & 0.060 & 0.905 \\
M10 & 0.533 & 0.048 & 0.953 \\
M11 & 0.516 & 0.047 & 1.000 \\
\hline
\end{tabular}

B. The nature of the factors

\begin{tabular}{|c|c|c|c|}
\hline Component & Description & \begin{tabular}{|l|l|l} 
Variable loading $(>$ & 0.40 & )
\end{tabular} & \\
\hline \multirow[t]{2}{*}{ M1 } & Ventilation & Ventilation with heat exchanger & .44 \\
\hline & & Three-glass window & .47 \\
\hline \multirow[t]{3}{*}{ M2 } & Insulation & Insulation roof & .49 \\
\hline & & Insulation wall & .47 \\
\hline & & Airborne heating distribution & -.43 \\
\hline \multirow[t]{2}{*}{ M3 } & Water reduction & Water reduced WC & .55 \\
\hline & & Water reduced water taps & .48 \\
\hline \multirow[t]{3}{*}{ M4 } & Heat pump & Water reduced WC & -.45 \\
\hline & & Central heating & .40 \\
\hline & & Heat pump & .59 \\
\hline \multirow[t]{2}{*}{ M5 } & Central heating & Central heating & .54 \\
\hline & & Solar energy & .78 \\
\hline M6 & Solar energy & Solar energy & .48 \\
\hline \multirow[t]{3}{*}{ M7 } & Waterborne distribution & Heat pump & -.42 \\
\hline & & Waterborne heating distribution & .74 \\
\hline & & Airborne heating distribution & .44 \\
\hline \multirow[t]{2}{*}{ M8 } & Three-glass window & Airborne heating distribution & -.48 \\
\hline & & Three-glass window & .60 \\
\hline \multirow[t]{3}{*}{ M9 } & Miscellaneous & Water reduced WC & .49 \\
\hline & & Water reduced water & -.62 \\
\hline & & Ventilation with heat exchanger & .41 \\
\hline \multirow[t]{3}{*}{ M10 } & Airborne heating & Ventilation with heat exchanger & -.59 \\
\hline & distribution & Airborne heating distribution & .43 \\
\hline & & Three-glass window & .42 \\
\hline \multirow[t]{2}{*}{ M11 } & Insulation wall & Insulation roof & -.69 \\
\hline & & Insulation wall & .67 \\
\hline
\end{tabular}

In table 2, the result of the principal component analysis is presented. Section A shows the eigenvalues and the proportion of the total variance for each component. High eigenvalues indicate that the component explain a large portion of the total variance among the variables. However, note that the principal component analysis does not say anything about the correlation between the environmental housing attributes, the constructed principal components, and house prices. In section $\mathrm{B}$, the principal components are presented and categorized according to the most important variables included in the construction of the component. The four first components explain around 50 per cent of the total variance in all the environmental housing attributes. 


\subsection{The Hedonic Price Equation}

We now turn to estimating the hedonic price equation. That is we conduct a regression of house prices against attributes that determine these prices. The regression coefficients are estimates of the hedonic (implicit) prices of these attributes. The benchmark model uses all attributes discussed and presented above.

We have used the stepwise regression approach in order trim down the hedonic price equation, and thus we follow Greene (2008); the "attractive strategy is then to adopt a general-to-simple, downward reduction of the model to the preferred specification". This approach goes through a step-by-step process of adding (forward stepwise regression) or eliminating (backward stepwise regression) variables until the best model is produced based on the search criteria. At each step, an F test is performed to determine if that variable is appropriate to include or exclude. The benchmark model and two stepwise regressions are presented in the Table 3. A Box-Cox transformation has been performed in order to analyze the functional form of the hedonic equation. The preferred model is the semilogarithmic specification where the dependent variable, but not the independent variables, has been transformed.

The results indicate that around 70 per cent of the variation in price can be explained by the included housing attributes and neighborhood characteristics. All the estimated parameters have expected sign and are of reasonable magnitude. If living area increases by one square meter, price is expected to increase by SEK $10,425(0.00417 * 2.5$ million $)$ and adding one more room increases the price by 2.072 per cent $\left(\left(\mathrm{e}^{0.02051}-1\right)^{*} 100\right)$. Sea view increases the expected value by 28 per cent and road traffic reduces the expected price by 5.1 per cent (or around SEK 150000).

Out of the eleven principal components, seven are significant (M2, M3, M5-M8 and M11). The component that includes waterborne heating distribution (M7) exhibits the highest economic impact together with three-glass window (M8). The results indicate that the components water reduced WC and water reducing taps (M3) as well as insulation (M2), solar energy (M6), central heating (M5), and insulation in the wall (M11) all have statistically significant positive hedonic prices and thereby a positive willingness to pay (WTP) attached to them. As the variable need of maintenance is included in the price equation, the environmental attributes is not picking up a well-maintenance effect. The Rsquare is slightly higher in the model using all variables but the stepwise regression (forward) model; has been used in the estimation of the utility parameters as it has the lowest AIC and BIC. 
Table 3. The Hedonic Price Equation

\begin{tabular}{|c|c|c|c|}
\hline & All variables & $\begin{array}{l}\text { Stepwise regression } \\
\text { (forward) }\end{array}$ & $\begin{array}{l}\text { Stepwise regression } \\
\text { (backward) }\end{array}$ \\
\hline Living area & $\begin{array}{l}.00404 \\
(8.83)\end{array}$ & $\begin{array}{l}.00417 \\
(10.72)\end{array}$ & $\begin{array}{l}.00444 \\
(10.60)\end{array}$ \\
\hline Other area & $\begin{array}{c}.00030 \\
(.76)\end{array}$ & - & - \\
\hline Lot size & $\begin{array}{l}.00007 \\
(1.12)\end{array}$ & - & - \\
\hline Number of rooms & $\begin{array}{l}.02148 \\
(2.01)\end{array}$ & $\begin{array}{l}.02051 \\
(1.94)\end{array}$ & $\begin{array}{l}.02010 \\
(1.88)\end{array}$ \\
\hline Age & $\begin{array}{c}-.00021 \\
(-.19)\end{array}$ & - & $\begin{array}{l}.00196 \\
(2.25)\end{array}$ \\
\hline Quality & $\begin{array}{l}.00482 \\
(2.20)\end{array}$ & $\begin{array}{l}.00501 \\
(2.68)\end{array}$ & $\begin{array}{c}.005917 \\
(3.09)\end{array}$ \\
\hline Need of maintenance & $\begin{array}{c}-.09546 \\
(-4.90)\end{array}$ & $\begin{array}{c}-.09269 \\
(-4.63)\end{array}$ & $\begin{array}{c}-.10288 \\
(-5.09)\end{array}$ \\
\hline Sea view & $\begin{array}{l}.24585 \\
(4.50)\end{array}$ & $\begin{array}{l}.24354 \\
(4.73)\end{array}$ & - \\
\hline Traffic & $\begin{array}{c}-.05478 \\
(-2.38)\end{array}$ & $\begin{array}{l}-.05185 \\
(-2.40)\end{array}$ & $\begin{array}{l}-.05417 \\
(-2.39)\end{array}$ \\
\hline Distance to CBD & $\begin{array}{l}-.00006 \\
(-2.30)\end{array}$ & $\begin{array}{c}-.00002 \\
(-4.31)\end{array}$ & $\begin{array}{c}-.00003 \\
(-5.06)\end{array}$ \\
\hline M1 (Ventilation) & $\begin{array}{c}-.00555 \\
(-.63)\end{array}$ & - & - \\
\hline M2 (Insulation) & $\begin{array}{l}.01257 \\
(1.40)\end{array}$ & $\begin{array}{l}.01654 \\
(2.36)\end{array}$ & $\begin{array}{l}.01956 \\
(2.47)\end{array}$ \\
\hline M3 (Water reduction) & $\begin{array}{l}.01724 \\
(1.81)\end{array}$ & $\begin{array}{l}.01707 \\
(1.87)\end{array}$ & $\begin{array}{l}.01844 \\
(1.92)\end{array}$ \\
\hline M4 (Heat pump) & $\begin{array}{c}-.00090 \\
(-.09)\end{array}$ & - & - \\
\hline M5 (Central heating) & $\begin{array}{l}.01221 \\
(2.47)\end{array}$ & $\begin{array}{l}.00798 \\
(1.71)\end{array}$ & - \\
\hline M6 (Solar energy) & $\begin{array}{l}.01891 \\
(2.19)\end{array}$ & $\begin{array}{l}.01913 \\
(2.34)\end{array}$ & $\begin{array}{l}.02022 \\
(2.31)\end{array}$ \\
\hline M7 (Waterborne distribution) & $\begin{array}{l}.02447 \\
(1.99)\end{array}$ & $\begin{array}{l}.02557 \\
(2.20)\end{array}$ & \\
\hline M8 (3-glass window) & $\begin{array}{l}.02211 \\
(2.04)\end{array}$ & $\begin{array}{l}.02584 \\
(2.50)\end{array}$ & $\begin{array}{l}.03244 \\
(3.09)\end{array}$ \\
\hline M9 (Miscellaneous) & $\begin{array}{c}.00325 \\
(.30)\end{array}$ & - & - \\
\hline M10 (Airborne distribution) & $\begin{array}{l}.01261 \\
(1.10)\end{array}$ & - & - \\
\hline M11 (Insulation wall) & $\begin{array}{c}.02151 \\
(1.83)\end{array}$ & $\begin{array}{c}.01891 \\
(1.65)\end{array}$ & $\begin{array}{l}.02377 \\
(2.01)\end{array}$ \\
\hline Constant & $\begin{array}{c}13.96082 \\
(70.96)\end{array}$ & $\begin{array}{c}13.89503 \\
(186.98)\end{array}$ & $\begin{array}{l}13.77478 \\
(213.48)\end{array}$ \\
\hline $\begin{array}{l}\text { R-square } \\
\text { AIC } \\
\text { BIC } \\
\text { Number of observation }\end{array}$ & $\begin{array}{c}.7466 \\
-41.87 \\
268.51 \\
585\end{array}$ & $\begin{array}{c}.7279 \\
-62.29 \\
103.17 \\
585\end{array}$ & $\begin{array}{c}.7212 \\
-50.34 \\
110.77 \\
585\end{array}$ \\
\hline
\end{tabular}

Note: Coefficients concerning sum-markets and month of sale are not shown in the table. White heteroskedasticity-robust t-statistics within brackets. 


\subsection{The Utility Function}

The utility parameters can be revealed by estimating the expenditure ratio equation given by (5). Table 4 presents the descriptive statistics concerning these expenditure ratios.

Table 4. Expenditure ratio.

\begin{tabular}{lccc}
\hline Variable & Mean & Standard deviation & Maximum \\
\hline Expratio (Insulation, M2) & .0190 & .0080 & .0668 \\
Expratio (Water reduction, M3) & .0170 & .0073 & .0573 \\
Expratio (Central heating, M5) & .0753 & .0271 & .2026 \\
Expratio (Solar energy, M6) & .0398 & .0146 & .1072 \\
Expratio (Waterborne distr., M7) & .0134 & .0068 & .0450 \\
Expratio (3-glass window, M8) & .0237 & .0093 & .0734 \\
Expratio (Insulation wall, M11) & .0063 & .0037 & .0263 \\
\hline
\end{tabular}

Note: The expenditure ratio for Expratio (Insulation, M2) is estimated as $W T P_{M 2} * M 2 / X$. Analogous definition for the other expenditures rates. $X$ (all other goods) is estimated as the difference between expected lifetime income $(I)$ and housing price $(P)$

Compared to spending on all other consumption, spending on environmental attributes is small. Households investing in central heating (M5) and solar energy (M6) investing a larger portion of their total consumption when buying that attribute, which is natural, as such investments are costly. For example, on average almost 5 per cent is spent on solar energy compared to all other consumption and almost 8 per cent is spend on central heating. Around 2 per cent of all other consumption is spent on the other environmental related characteristics except for insulation in the wall (M11). Table 5 shows the correlation between the expenditure ratios and the household characteristics.

Table 5. Correlation between expenditures on environmental housing attributes and household characteristics.

\begin{tabular}{l|ccc}
\hline & Family size & $\begin{array}{c}\text { Higher } \\
\text { Education }\end{array}$ & $\begin{array}{c}\text { Environmental } \\
\text { Awareness }\end{array}$ \\
\hline Expratio (Insulation, M2) & .0821 & -.0738 & -.0126 \\
Expratio (Water reduction, M3) & .0390 & -.0787 & .0478 \\
Expratio (Central heating, M5) & .0446 & -.0717 & .0104 \\
Expratio (Solar energy, M6) & .0311 & -.0461 & .0338 \\
Expratio (Waterborne distr., M7) & .0152 & -.0351 & .0488 \\
Expratio (3-glass window, M8) & .0312 & -.0870 & .0163 \\
Expratio (Insulation wall, M11) & .0114 & -.0420 & .0298 \\
\hline
\end{tabular}

All expenditure ratios are negatively correlated to higher education, but positively to family size. Hence, larger families with lower education spend more on environmental housing attributes in relation to all other consumption. The correlation between the expenditure ratios and environmental awareness is positive except for insulation. Hence, households that perceive themselves as environmentally aware seem to spend more on environmental housing characteristics in relation to all other consumption than others do. The next step is to estimate equation 5 in which the expenditure 
ratios are related to family size, educational background, environmental awareness and consumption of housing attributes.

As a number of equations are to be estimated simultaneously and we have a problem with endogeneity, a three-stage least square approach will be used. Three-stage least square is a combination of seemingly unrelated regression developed by Zellner (1962) and two-stage regression with instrument variables (see Zellner and Theil, 1962). In a multiple equation system like ours where the same data set is used, the dependent variable as well as some of the independent variables differ between the equations, the errors may be correlated between the equations. Three-stage least squares may, therefore, be more efficient than two-stage least squares (see e.g. Madansky, 1964, Belsley, 1988, and Greene, 2008).

Table 6. Estimate of the Utility Parameter concerning Environmental Awareness (Equation 4)

\begin{tabular}{|c|c|c|c|c|}
\hline & Utility Function 1 & arameter & & \\
\hline & $\begin{array}{c}\text { Environmental } \\
\text { Awareness } \\
\text { (exogenous) }\end{array}$ & & $\begin{array}{c}\text { Environmental } \\
\text { Awareness } \\
\text { (endogenous) }\end{array}$ & \\
\hline Insulation & $.00059^{\mathrm{c}}$ & $(1.08)$ & .00008 & $(0.65)$ \\
\hline Water reduction & $.00196^{\mathrm{a}}$ & $(3.50)$ & $.00366^{\mathrm{a}}$ & $(2.68)$ \\
\hline Central heating & .00024 & (1.18) & $.00133^{\mathrm{a}}$ & $(2.65)$ \\
\hline Solar energy & $.00287^{\mathrm{a}}$ & $(3.25)$ & $.00463^{\mathrm{b}}$ & $(2.14)$ \\
\hline Waterborne distr. & $.00164^{\mathrm{a}}$ & $(2.90)$ & $.00268^{\mathrm{c}}$ & (1.94) \\
\hline 3-glass window & .00079 & $(1.17)$ & .00018 & $(0.11)$ \\
\hline Wall insulation & $.00069^{\mathrm{c}}$ & $(1.93)$ & $.00167^{\mathrm{c}}$ & $(1.91)$ \\
\hline
\end{tabular}

Note. Three-Stage Least Square Estimates. Instruments: income, square of income, family size, square of family size, educational background, composting, use of low-energy lamps, waste sorting, sub-market and crossproducts. ${ }^{a}$ significant at $1 \%$ level, ${ }^{\text {b }}$ significant at $5 \%$ level and ${ }^{c}$ significant at $10 \%$ level. Standard errors are not shown to reduce space. t-statistics within brackets. Number of observations: 545.

As some of the independent variables are endogenous, ordinary least square regression or seemingly unrelated regression may produce spurious results. The instrument variable approach may avoid this bias if the instrument variables are valid (see Murray, 2006). In our case, the endogeneity is connected to the simultaneous choice of marginal price and the level of the housing attribute. In accordance with Quigley (1982), Chattopadhyay (1999) and Wilhelmsson (2002) we are using socio-economic characteristics of the household as instruments, for example, income and square of income, as well as family size, square of family size, and educational background. It may also be that the variable environmental awareness is endogenously determined, as it is self-reported. The question is, if the household bought the house because they are environmental aware or after the purchase use environmental awareness as justification for the expensive purchase. That is, causality is not obvious. We, therefore, estimate two models. In the first model environmental awareness is treated as being an exogenous variable while it is treated as endogenous in the second. Instrument variables for environmental awareness are used and they are assumed to be highly correlated with the 
environmentally awareness but not with the error term. Instrument variables are composting, use of low energy light bulbs and waste separation. In table 6, the results from the three-stage procedure are presented.

The results imply that environmental awareness have a significant effect on the form of the household utility function. The impact seems to be especially strong concerning the attribute M3 (water reduction), but also for M5 (central heating) and M6 (solar energy). The t-values are slightly higher in the model assuming environmental awareness as exogenous variable compared to the model where it is assumed it is endogenous. Environmental awareness concerning central heating is not significant in the first model, but significant in the second. Moreover, environmental awareness concerning waterborne distribution system is significant in the former, but not in the latter. Given that our instrument variables are valid, the results suggest that the variable is not endogenous ant that environmental awareness affects willingness to pay and not vice versa. With the estimates of the utility parameters known, the estimates for non-marginal WTP can be calculated.

\subsection{Non-marginal WTP}

Table 7 below shows the non-marginal WTP for the environmental related housing attributes. Using the same method as Chattopadhyay (1999), we calculate the average non-marginal WTP for a 25 per cent increase in a given housing attribute level. The non-marginal WTP has been estimated for each household. In the table, the average non-marginal WTP is presented for all households and for households with an income larger than one standard deviation from the average income.

Table $7 . \quad$ Non-marginal WTP (Translog utility function), SEK.

\begin{tabular}{|c|c|c|c|c|c|c|}
\hline \multirow[b]{3}{*}{ Insulation } & \multicolumn{3}{|l|}{ All } & \multicolumn{3}{|l|}{$\begin{array}{l}\text { High } \\
\text { Income }\end{array}$} \\
\hline & Not aware & Aware & Difference & Not aware & Aware & Difference \\
\hline & 219,792 & 223,862 & $1.8 \%$ & 319,396 & 321,894 & $0.8 \%$ \\
\hline $\begin{array}{l}\text { Water } \\
\text { reduction }\end{array}$ & 192,707 & 204,207 & $5.8 \%$ & 279,501 & 292,425 & $4.5 \%$ \\
\hline $\begin{array}{l}\text { Central } \\
\text { heating }\end{array}$ & 41,689 & 44,914 & $7.5 \%$ & 60,445 & 63,717 & $5.3 \%$ \\
\hline $\begin{array}{l}\text { Solar } \\
\text { energy }\end{array}$ & 413,447 & 428,692 & $3.6 \%$ & 601,548 & 614,389 & $2.1 \%$ \\
\hline $\begin{array}{l}\text { Waterborne } \\
\text { distr. }\end{array}$ & 213,416 & 222,419 & $4.1 \%$ & 310,608 & 318,735 & $2.6 \%$ \\
\hline $\begin{array}{l}3 \text {-glass } \\
\text { window }\end{array}$ & 143,751 & 145,808 & $1.4 \%$ & 207,162 & 208,015 & $0.4 \%$ \\
\hline $\begin{array}{l}\text { Wall } \\
\text { insulation }\end{array}$ & 83,833 & 88,705 & $5.6 \%$ & 122,691 & 127,443 & $3.8 \%$ \\
\hline
\end{tabular}


Not surprisingly, the non-marginal WTP for all the environmental related housing attributes is higher for environmental aware households. On average, environmentally aware households show a nonmarginal WTP about 2-4 per cent higher for insulation, solar energy and waterborne distribution system and around 5-8 per cent when it concerns water reducing technologies, wall insulation and central heating. Households with a high income are, in general, willing to pay more for a non-marginal changes, but the difference between environmental aware households and not aware are more or less the same as for all households.

\section{Policy implications}

There may be several reasons for why there is a positive, and significant, willingness to pay for some of the attributes studied. Perhaps the most obvious is that the attributes provide a mean to reduce other costs, typically associated with energy or water consumption. Thus, we would expect to observe positive willingness to pay even in a situation where the agents have no preferences for the environment whatsoever. From a policy point of view this leads to the obvious conclusion that one may induce a larger use of environmental technology in housing through increasing the cost of harming the environment, that is, if energy production causes a negative externality, the government may introduce a corrective energy tax. This is of course well known and standard proceedings in many countries, not least Sweden from where the data is collected. What is interesting is that this does not require any environmental awareness among the agents who will only respond to the incentives provided by the tax.

The analysis above contributes to this well known outcome by studying if there exists an additional environmental awareness effect. That is, is it the case that - at least some - agents demand environmental attributes, not only because they reduce other costs the agents may have but because they are good for the environment? This is interesting in its own right as one may argue both for and against the existence of such an effect. On the one hand, the environment is obviously important for present and future generations and, hence, there should be a willingness to pay for it. On the other hand, the environment exhibits strong public good characteristics and, especially as there are corrective taxes used on the studied market, it should be handled by a central government and financed by taxes.

However, the analysis is also of importance for policy design. In particular, it has impact on the applicability of information campaigns. If it is the case that agents that are environmentally aware do not have a higher willingness to pay, it becomes harder to justify such campaigns. The present study does not address to what extent information campaigns are capable of influencing consumers' preferences. That is, whether they may make people "environmentally aware". The point here is rather 
to investigate whether environmentally aware households exhibit a higher willingness to pay for environmental housing attributes. This is important since, if this is the case, it motivates implementing policies aimed at increasing the environmental awareness as then more may be achieved with a given economic policy instrument or, put another way, a given goal may be achieved with less intervention in the economy, e.g., lower energy taxes. If, on the other hand, there were no connection between willingness to pay and environmental awareness, it becomes much harder to argue for spending resources on information campaigns etc. There would still be other reasons for such policies, e.g., to increase acceptability for economic instruments, but no real ground for expecting that the information would lead to changes in behavior on the housing market.

The analysis shows that agents who label themselves as environmentally aware actually exhibit a larger willingness to pay for many of the environmental attributes. Thus, increasing the environmental awareness in a society lead to a larger willingness to pay for environmental attributes, this in turn may lead to a lower environmental impact from the housing sector. This result may thus be used to promote the use of policies such as information campaigns. However, a closer look at the results yields that the largest impact is found for measures that do not require large investment, for example, installing water reducing taps. For more costly investment such as retrofitting insulation or installing solar panels, the difference in willingness to pay between those who label themselves environmentally aware and those who do not is much smaller. A plausible explanation may be that larger investment requires more of thorough calculations, leaving less room for subjective valuations. To the extent that it is the large investment that really can make a difference, this observation may be troubling.

Thus, the results from the analysis above suggest that efforts towards increasing environmental awareness may be justifiable, but also that - in order to influence choices of more substantial nature these efforts should be coupled with economic incentives. That is, information campaigns leading to increased awareness may be justifiable, but they are rather a complement than a substitute to economic policy instruments if one strives for more substantial changes in behavior.

\section{Conclusions}

It is not obvious that that environmental attributes should be associated with a positive willingness to pay. After all, some environmental attributes may very well be associated with characteristics that are not desirable, for instance, water reducing taps may be perceived as providing less comfort. The first conclusion to be drawn from the analysis in this paper is thus that there is a positive, if any, willingness to pay for environmental attributes. That is, none of the attributes examined exhibits a negative and significant willingness to pay. 
To a large extent the environmental attributes we study will reduce costs for the households, for instance by reducing energy or water consumption. A positive willingness to pay for these attributes may thus exist even without any environmental concerns on the households' behalf. Therefore, it is an interesting finding that households that state that they perceive themselves as environmentally aware actually show a significantly higher willingness to pay for environmental housing attributes.

We have argued that this finding is interesting in itself, but also that it has policy implications as it justifies spending resources on efforts aimed at increasing the environmental awareness among the general public. However, the analysis reveals a pattern indicating that the impact from environmental awareness on willingness to pay is lower (although still significant) for attributes associated with larger investments, e.g., heating pumps or solar energy. This leads us to conclude that there is room for information campaigns and similar policy measures, but these needs to be complemented with economic policy instrument in order to influence behavior on a larger scale. 


\section{Reference}

Axsen J., Mountain, D.C., and Jaccard M. (2009). Combining stated and revealed choice research to simulate the neighbor effect: The case of hybrid-electric vehicles, Resource and Energy Economics, Vol. 31, 221-238.

Banfi, S., Farsi, M., Filippini, M., and Jakob, M. (2008). Willingness to pay for energy-saving measures in residential buildings, Energy Economics, Vol. 30, 503-516

Belsley, D.A. (1988). Two- or Three-stage least squares? Computer Science in Economics and Management, Vol.1, 21-30.

Beron, K., Murdoch, J. and Thayer, M. (2001). The benefits of visibility improvement: New evidence from the Los Angeles metropolitan area, Journal of Real Estate Finance and Economics, Vol 22(2-3), $319-337$

Bourassa, S.C., Hoesli, M. and Peng, V.S. (2003). Do housing submarkets really matter? Journal of Housing Economics, Vol.12, 12-28.

Brasington, D.M. and Hite, D. (2005). Demand for environmental quality: A spatial hedonic analysis, Regional Science and Urban Economics, Vol. 35(1), 57-82

Chattopadhyay, S. (1999). Estimating the Demand for Air Quality: New Evidence Based on the Chicago Housing Market. Land Economics, Vol.75(1), 22-38.

Chattopadhyay, S. (2000). The effectiveness of McFadden's nested logit model in valuing amenity improvement, Regional Science and Urban Economics, Vol. 30, 23-43

Des Rosiers, F., Thériault, M. and Villeneuve, P.-Y. (2000). Sorting out access and neighbourhood factors in hedonic modeling. Journal of Property Investment and Finance, Vol.18(3), 291-315.

Dunteman, G.H. (1992). Principal Components Analysis, SAGE Publication.

Goodman, A.C. (1978). Hedonic prices, price indices and housing markets. Journal of Urban Economics, Vol.5(4), 471-484.

Greene, W.H. (2008). Econometric Analysis. Pearson Prentice Hall, New Jersey, US.

Hite, D., Chern, W., Hitzhusen, F., and Randall, A. (2001). Property value impacts of an environmental disamenity: The case of landfills, Journal of Real Estate Finance and Economics. Vol. $22(2-3), 185-202$

Hoehn, J.P., Berger, M.C. and Blomquist, G.C. (1987). A hedonic model of interregional wages, rents, and amenity values, Journal of Regional Science, Vol. 74(4), 605-620

Kiel, K. A. and McClain K. T. (1985). House prices through siting decision stages: The case of an incenirator from rumor through operation, Journal of Environmental Economics and Management, Vol. 25(2), 241-255

Kohlhase, J. (1991).The impact on toxic waste sites on housing values, Journal of Urban Economics, Vol. 30(1), 1-26 
Lau, L.J. and Mitchell B.M. (1971) "A Linear Logarithmic Expenditure System: An Application to U.S. Data," paper presented at the Second World Congress of the Econometric Society, Cambridge, England. Abstracted in Econometrica, 39 (1970), 87-88.

Longo, A., Markandya, A., and Petrucci, M. (2008). The internalization of externalities in the production of electricity: Willingness to pay for the attributes of a policy for renewable energy, Ecological Economics, Vol. 67(1), 140-152

Madansky, A. (1964). On the efficiency of three-stage least-squares estimation, Econometrica, Vol.31(1-2), 51-56.

Murray, M.P. (2006). Avoiding Invalid Instruments and coping with weak Instruments. Journal of Economic Perspective, Vol.20(4), 111-132.

Nelson, A.C., Genereux, J. and Genereux, M. (1992). Price effects of landfills on house values, Land Economics, 68(4), 359-365

Potoglou, D., and Kanaroglou, P.S., (2007). Household demand and willingness to pay for clean vehicles, Transportation research Part D, Vol. 12, 264-274

Quigley, J. (1982). Nonlinear Budget Constraints and Consumer Demand: An Application to Public Programs for Residential Housing, Journal of Urban Economics, Vol. 12, 177-201.

Rosen, S. (1974), Hedonic Prices and Implicit Markets: Product Differentiation in Pure Competition, Journal of Political Economy, Vol. 82(1), 34-55

Scarpa, R., and Willis, K., (2010). Willingness-to-pay for renewable energy: Primary and discretionary choice of British households' for micro-generation technologies, Energy Economics, Vol. 32, 129-136

Smith, V. K. and Deyak, T. A. (1975). Measuring the impact of air pollution on property values, Journal of Regional Science, Vol. 15(3), 277-288

WCED (1997), Our Common Future, World Commission on Environment and Development, Oxford: Oxford University Press. ISBN 0-19-282080-X

Wilhelmsson, M. (2002). Household Expenditure Patterns for Housing Attributes: A Linear Expenditure System with Hedonic Prices, Journal of Housing Economics, Vol.(11), 75-93.

Wilhelmsson, M. (2008a). Evidence of Buyer Bargaining Power in the Stockholm Residential Real Estate Market. Journal of Real Estate Research, Vol.30(4),475-499.

Wilhelmsson, M. (2008b). House Price Depreciation Rates and Level of Maintenance. Journal of Housing Economics, Vol.17(1), 88-101.

Zellner, A. (1962). An efficient method of estimating seemingly unrelated regression equations and tests for aggregation bias. Journal of American Statistical Association, Vol.(57), 348-368.

Zellner, A. and Theil, H. (1962). Three-stage least square: Simultaneous Estimation of simultaneous Equations. Econometrica, Vol.30(1), January, 54-78. 